\title{
Significado de competências pedagógicas na formação docente de enfermagem: um estudo fenomenológico
}

\author{
Meaning of pedagogical competences in nursing teacher training: a phenomenological study \\ Significado de las competencias pedagógicas en la formación docente de enfermería: un estudio \\ fenomenológico
}

\begin{abstract}
Sandra Conceição Ribeiro Chicharo' $\odot$, Rose Mary Costa Rosa Andrade Silva ${ }^{\oplus}$, Eliane Ramos Pereira ${ }^{\prime} \odot$,

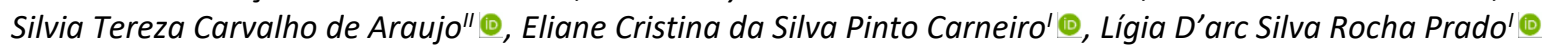

'Universidade Federal Fluminense, Niterói, RJ, Brasil; Universidade Federal do Rio de Janeiro, Rio de Janeiro, RJ, Brasil

\begin{abstract}
RESUMO
Objetivo: descrever as competências pedagógicas necessárias ao docente de enfermagem, sob a ótica do egresso do mestrado profissional de ensino na saúde e compreender os seus sentimentos em relação a sua formação docente. Método: estudo qualitativo com abordagem fenomenológica, tendo a seguinte questão como pergunta norteadora: qual a sua percepção sobre competências pedagógicas após um mestrado de ensino na saúde? Participaram da entrevista quatro enfermeiros mestres em ensino na saúde. Resultados: emergiram sentimentos como impotência, gratidão e negação, sobre a organização, interação e intersubjetividade e habilidades e dualismo psicofísico. Considerações finais: compreendendo o fenômeno estudado, afirmamos que a formação docente do mestrado profissional é uma vivência de sentimentos conflituosos, por vezes dolorosos para os seus egressos de enfermagem, o estudo visa trazer democratização dos espaços de trabalho, desenvolvimento da capacidade de ensinar de todos os atores envolvidos e busca de soluções criativas para os problemas encontrados.

Descritores: Filosofia; Programas de Graduação em Enfermagem; Educação em Enfermagem; Docentes de Enfermagem.
\end{abstract}

\begin{abstract}
Objective: to describe the pedagogical skills needed by teachers of nursing, in the view of alumni of the professional master's degree in health education, and to understand their feelings concerning their teacher training. Method: this qualitative, phenomenological study posed the following guiding question: what is your perception of pedagogical skills after a master's degree in teaching in health? Four nurses with master's degrees in health education participated in the interview. Results: feelings such as impotence, gratitude, and denial emerged with regard to organization, interaction, intersubjectivity, skills and psychophysical dualism. Final considerations: now the phenomenon studied is understood, it can be said that the professional master's teacher training is an experience that rouses conflicting - and sometimes painful - feelings for nursing graduates. The study aimed to help democratize workspaces, develop capacity to teach by all the actors involved, and find creative solutions to the problems encountered.
\end{abstract}

Descriptors: Philosophy; Education Nursing, Diploma Programs; Education, Nursing; Faculty Nursing.

\section{RESUMEN}

Objetivo: describir las competencias pedagógicas que necesita el profesor de enfermería, desde la perspectiva del egresado del Máster profesional en educación para la salud y comprender sus sentimientos con respecto a su formación de profesor. Método: estudio cualitativo con un enfoque fenomenológico, cuya pregunta orientadora fue la siguiente: ¿Cuál es su percepción en cuanto a competencias pedagógicas después de un Máster en educación para la salud? Cuatro enfermeras con Máster en educación para la salud participaron en la entrevista. Resultados: surgieron sentimientos como impotencia, gratitud y negación, sobre organización, interacción e intersubjetividad y habilidades y dualismo psicofísico. Consideraciones finales: al comprender el fenómeno estudiado, afirmamos que la formación docente del Máster profesional es una experiencia de sentimientos conflictivos, a veces dolorosos para los egresados de enfermería, el estudio tiene como objetivo traer la democratización de los espacios de trabajo, el desarrollo de la capacidad de enseñanza de todos los actores involucrados y la búsqueda de soluciones creativas a los problemas encontrados.

Descriptores: Filosofía; Programas de Graduación en Enfermería; Educación em Enfermería; Docentes de Enfermería.

\section{INTRODUÇÃO}

Nós, enfermeiros, estamos lidando diariamente com o processo de ensino, seja nos projetos de educação em saúde na assistência direta ao paciente, nas atividades gerenciais frente à equipe interdisciplinar nos programas de educação permanente ou atuando diretamente na formação de futuros profissionais ${ }^{1}$.

Indagamos se o enfermeiro, ao concluir sua graduação, estaria preparado para exercer tais funções, uma vez que nos cursos de graduação em enfermagem, a ênfase é geralmente mecanicista, dada aos aspectos biológicos do processo de assistir o paciente, de acordo com o modelo biomédico hegemônico, não tendo em suas diretrizes um viés a 
formação de docente na área da saúde. Dessa forma nós, os enfermeiros assistenciais, que por tendência ou opção pessoal, passamos a exercer atividades docentes, o fazemos de maneira intuitiva, seguindo modelos que nos foram significativos durante nossa formação acadêmica².

Profissionais de diversas áreas adentram no campo da docência do ensino superior como decorrência natural de suas atividades e por razões e interesses variados e, na maioria das vezes, nunca se questionaram sobre o que é ser professor $^{3}$. Dessa forma, atuam no ensino superior sem terem sido preparados para o desempenho da docência, por não terem estas atribuições dentro dos programas de graduação em enfermagem.

Os saberes da prática docente são múltiplos e se originam de: saberes profissionais, que são saberes da ciência da educação aliados aos saberes da ideologia da educação; os saberes disciplinares, socialmente definidos e selecionados pela instituição universitária e seu projeto de curso; os saberes curriculares, provenientes dos saberes sociais da instituição escolar; e os saberes experienciais, elaborados no exercício da prática docente, que são oriundos pela experiência individual ${ }^{4}$.

Nesse sentido, evidenciamos a importância da formação permanente e continuada do enfermeiro professor no ensino superior, uma vez que só a formação profissional específica e/ou uma especialização na área de conhecimento, ou treinamento de conteúdos teóricos, é insuficiente para capacitar um profissional para a docência no ensino superior ${ }^{5}$.

Algo em nosso cerne aflora sobre a formação dos professores, como verdadeiros educadores, formadores de profissionais não só aptos ao mercado de trabalho, mas a serem cidadãos, a terem consciência crítica, a agirem seguindo preceitos éticos e legais da profissão e da sociedade, estando aptos a conviverem com os demais membros da equipe de saúde e da família, em prol da qualidade de vida dos pacientes.

Como em muitas ocupações desse gênero, semiprofissionais, relativamente autônomas, baseadas em relações humanas e que exigem um envolvimento pessoal do trabalhador, principalmente no plano afetivo, a docência é um dos trabalhos de limites imprecisos e variáveis de acordo com os edifícios e as circunstâncias, e também segundo os estabelecimentos e os quarteirões e localidades ${ }^{6: 112}$.

Eis que surge nossa indagação de que só a formação profissional específica, uma especialização na área de conhecimento, ou treinamentos de conteúdos teóricos, é insuficiente para trazer a qualquer profissional a capacitação para a docência. Mas ao contrário, só fortalece as perspectivas referentes a essa temática, de que devemos, nós docentes, termos uma formação própria para a docência e, nesse raciocínio, nos deparamos com os mestrados profissionais em saúde?.

Torna-se relevante questionar se os professores estão capacitados para uma prática docente que esteja em consonância com as novas perspectivas que se colocam na educação em enfermagem. Essa é uma questão relevante, quando verificamos que o despreparo dos docentes no ensino universitário, de modo geral, tem sido apontado como um dos fatores que comprometem a qualidade da formação em nível superior dos profissionais da área da saúde ${ }^{8,9}$.

Por sermos docentes e profissionais da saúde, percebemos, através da nossa prática diária e nas dificuldades que vivenciamos in loco, a necessidade de uma formação específica em docência para atuar de forma consciente e conhecer as competências necessárias ao enfermeiro docente. Sendo assim, é preciso desmistificar a ideia de que para ensinar enfermagem basta ter domínio do conteúdo teórico-prático das disciplinas do curso, e com isso pontuar a importância das disciplinas pedagógicas ao profissional de enfermagem dentro de suas diretrizes e dos programas de graduação em enfermagem.

Perante o exposto, este estudo objetivou descrever as competências pedagógicas necessárias ao docente de enfermagem, sob a ótica do egresso do mestrado profissional de ensino na saúde, e compreender os seus sentimentos em relação a sua formação docente.

\section{MÉTODO}

Tratou-se de um estudo descritivo, com abordagem qualitativa e cunho fenomenológico à luz de Maurice MerleauPonty ${ }^{10}$. A compreensão do fenômeno em evidência levou-nos a escolher um caminho metodológico que possibilitasse a aproximação das vivências dos mestrandos em ensino na saúde, abarcando o pensar, o sentir e o agir. Dessa forma, optamos pela pesquisa qualitativa, de cunho fenomenológico, por se tratar de um ramo da filosofia que valoriza os significados que as pessoas atribuem aos seus sentimentos vividos, revelados a partir das suas descrições ou discursos. Entendemos que essa vertente metodológica possibilita uma melhor compreensão acerca da vivência dos mestrandos em ensino na saúde, bem como dos sentimentos que os envolvem na busca pelas competências pedagógicas ao enfermeiro docente ${ }^{11}$.

A investigação teve como cenário um programa de mestrado profissional de uma Universidade Federal do Estado do Rio de Janeiro, na cidade de Niterói. Esse programa de pós-graduação stricto sensu foi escolhido como espaço de 
pesquisa por ser um local onde desenvolvemos nossas atividades de pesquisa e ensino, e por ser, sobretudo, um programa de educação que visa melhorar a formação dos profissionais de saúde. Nesse ambiente, os egressos enfermeiros experimentam situações de aprendizagem que os fazem buscar sentimentos sobre a sua formação pedagógica para prática docente.

Os participantes do estudo, sobre a temática em questão, foram os enfermeiros egressos das duas primeiras turmas do programa de mestrado profissional. Os critérios de inclusão para participação deste estudo foram: ser enfermeiro egresso do programa de mestrado em ensino na saúde e ter interesse e disponibilidade para participar do estudo. Optou-se por excluir da amostra do estudo os alunos que já atuavam na docência.

Quatro enfermeiros egressos do programa foram selecionados para participar da investigação. Entre eles, dois atuam exclusivamente na atenção básica e as outras duas intercalam atividades entre a atenção básica e a atenção hospitalar. Esse número de depoentes foi estabelecido no decorrer da etapa de campo, em decorrência de um número reduzido de egressos enfermeiros que não atuavam na docência antes de iniciarem o mestrado, bem como pela recusa de dois participantes. Para preservarmos o anonimato desses depoentes, optamos por identificá-los com nomes de flores.

A produção dos dados foi feita através da técnica da entrevista de natureza fenomenológica, a partir da seguinte questão: qual a sua percepção sobre competências pedagógicas após um mestrado de ensino na saúde? Todos os egressos enfermeiros do programa de mestrado profissional em ensino em saúde investigado foram convidados a participar da pesquisa. Além disso, eles foram informados sobre os objetivos, a importância de sua colaboração para o desenvolvimento da pesquisa, o caráter confidencial de suas respostas, a fidedignidade com que os dados seriam trabalhados e o direito de desistir de participar do estudo em qualquer momento. Aqueles que voluntariamente consentiram sua participação e assinaram o Termo de Consentimento Livre e Esclarecido (TCLE) foram incluídos como depoentes na etapa de campo.

A coleta de dados foi realizada pela pesquisadora responsável pelo estudo, enfermeira, mestranda do programa de mestrado profissional de ensino na saúde. As entrevistas foram realizadas individualmente no mês de julho de 2014, previamente agendadas de acordo com a disponibilidade de data, hora e hora dos profissionais, sendo gravadas, após autorização dos depoentes.

Na sequência, elaboradas as notas do diário de campo, transcrição e leitura cuidadosa das entrevistas, a fim de que nenhuma informação relevante fosse desconsiderada pela pesquisadora e encaminhas aos depoentes para aprovação. As informações foram analisadas de acordo com a trajetória fenomenológica, que consiste em três momentos: descrição, redução e a compreensão fenomenológica. Essa forma de registro possibilitou a captação, com fidelidade, do discurso do entrevistado ${ }^{11}$.

O protocolo de pesquisa foi aprovado pelo Comitê de Ética em Pesquisa da instituição, a fim de cumprir o que preceitua a Resolução n. 0 466/12 do Conselho Nacional de Saúde (CNS).

\section{RESULTADOS E DISCUSSÃo}

As entrevistas geraram as seguintes categorias temáticas à pesquisa: organização; interação e intersubjetividade; habilidades e dualismo psicofísico.

\section{Organização}

A análise indicou uma percepção da necessidade de organização prévia da aula e que esta, também foi amplamente percebida no decorrer do mestrado, sendo conceituada pelos sujeitos da pesquisa como uma competência pedagógica, estabelecidos pelos programas de graduação em enfermagem.

[...] para se dar aula tem que se dedicar, fazer um estudo bacana e tudo, e aí até então não entrei ainda. Mas é sempre muito importante porque desenvolve justamente este eixo pedagógico que fica faltando na nossa formação. (Orquídea).

[...] sabemos que ter um planejamento é importante, sem planejamento é difícil a gente caminhar, mas você tem um planejamento, você chega lá e as coisas acontecem de uma forma diferente naquele dia, você precisa mudar a dinâmica para conseguir seguir com sua aula, com o trabalho que você está fazendo de forma satisfatória[...]. (Hortência).

De fato, é importante que o docente de enfermagem tenha a capacidade de organizar os conteúdos, desenvolver técnicas educativas, planejar, implementar e participar de programas de formação e qualificação, bem como ter facilidade de comunicação, liderança e dinamismo. Desse modo, poderá incentivar o pensamento do aluno e sua interação com a sociedade, trazendo ao mercado de trabalho um profissional responsável com o cuidado e com suas interações multidisciplinares ${ }^{12}$. 


\section{Interação e intersubjetividade}

Além do conhecimento disciplinar, da interação com os discentes e das experiências escolares, os professores, ao longo da sua jornada dentro do âmbito escolar, e de suas diretrizes, servem de exemplo, pois levamos destes alguns traços que são reproduzidos por nós em sala de aula. Com a análise da entrevista, foi possível identificar as principais mudanças da prática vivenciadas no decorrer e término do mestrado.

[...] A questão pedagógica que foi mais enriquecida, foi com relação ao trabalho que pode ser feito em sala de aula partindo da interação do aluno com base na participação do aluno na atividade da aula. Nesse ponto eu senti uma riqueza evidente, porque achava que eu já explorava esse campo e alguns professores do mestrado me mostram que esse universo era infinito, que eu podia avançar muitíssimo mais. (Açucena).

[...] eu acredito que essas coisas eu aprendi bastante, com o curso que fiz, lá me ajudou muito. Eu fiz minha pesquisa aqui, eu fiz em cima da educação permanente, eu acho que essa minha troca com os profissionais daqui foi bastante produtiva, foi uma coisa orientada pelo mestrado, que eu consegui desenvolver no meu serviço, mas que foi me dando mais segurança para o que eu desenvolvo atualmente. Já me sinto bem mais segura, eu ainda uso muita coisa que eu aprendi lá. (Hortência).

[...] Primeiro foi eu perceber a minha ligação com a educação, o próprio conhecimento meu como educadora, como eu percebi enquanto educadora, enquanto poder desenvolver, enquanto aprendizado podendo ser protagonista disso junto com os alunos do conhecimento, sedimentar minha identidade como educadora. (Açucena).

Tais depoimentos revelaram que a maior parte dos sujeitos percebe que o mestrado influenciou a sua formação profissional, ampliou suas possibilidades diante das dificuldades apresentadas nas suas práticas diárias, desde a escrita de um relatório até o relacionamento com seus colegas de trabalho, a forma de passar instruções e preparar sua equipe para atividades, de perceber as necessidades docentes e se relacionar com essas, pois tal interação é oriunda da intersubjetividade dos sujeitos envolvidos ${ }^{10,13}$.

\section{Habilidades e dualismo psicofísico}

$\mathrm{Na}$ enfermagem, a busca pelos conhecimentos de didática vem conduzir indagações que tencionam a implementação de uma prática docente, capaz de unir teoria à prática com técnicas educacionais atuais e envolventes, formando novos enfermeiros com pensamento crítico reflexivo sobre seu exercício profissional e na edificação de uma sociedade responsável, relacionando ao problema da herança do modelo biomédico e do dualismo psicofísico ${ }^{10,14}$.

[...] De conhecimento, sempre qualquer coisa voltada ao estudo da área da educação, a coisa do coletivo, da dúvida, dos questionamentos, do que você pode estar trabalhando para melhorar, melhorar o que o outro pensa em melhorar, não o quero que o outro melhore; o que posso tirar daquele outro para que ele possa melhorar a questão da educação permanente e da formação pedagógica, é isso o que posso estimular no outro para que ele possa melhorar, eu penso assim, nesse conhecimento dessa forma. (Lírio).

[...] Acho que você desenvolve um olhar crítico. Como eu trabalhei muito com a reflexão na ação, de Schon, depois ampliado, entre outros, é claro que você não é o mesmo, óbvio, você entra de uma forma, fazendo uma certa prática, você amplia seu critério, sua criticidade. (Orquídea).

[...] A forma como tudo que a gente vai desenvolvendo, lá dentro, ainda no mestrado, a gente nem percebe, mas quando a gente sai, pega um artigo para analisar ou senta para escrever alguma coisa, igual esse relatório que a gente estava fazendo, minha forma de escrever já é diferente, eu já consigo construir, organizar as coisas de uma forma diferente e eu atribuo esse diferencial a ter cursado o mestrado. (Hortência).

$O$ docente de enfermagem tem diante de si a responsabilidade de formar profissionais críticos, analíticos e com competência para prestar uma assistência de enfermagem de qualidade. Para isso, devem rever constantemente sua atuação e conhecimento com relação ao ensino ${ }^{15}$.

A partir da análise dos dados, vislumbramos os principais sentimentos que envolvem os mestrandos em relação a sua formação pedagógica para a docência de enfermagem, reunidos em unidades de significado da seguinte maneira: organização, interação e intersubjetividade, e habilidades e dualismo psicofísico. Todos apresentavam uma relação com o fazer, isto é, com a implementação de ações para lidar com o outro enquanto docente ou educador. As unidades de significado apreendidas representam perspectivas do fenômeno estudado e refletem como os enfermeiros, mestrandos em ensino na saúde, expressam esses sentimentos diante da sua formação pedagógica, estando mergulhados nesse contexto ${ }^{11}$.

O processo ensino-aprendizagem deve ser contextualizado no momento histórico, político, econômico e social de um grupo, pois ele é dinâmico e exige do docente uma constante reflexão e avaliação da sua postura. Nesse sentido, o homem é um ser-no-mundo e como tal, é atravessado pelas circunstâncias que vivência ${ }^{16}$. 
Embora seja o professor o responsável pela formação geral do aluno e propicie seu desenvolvimento crítico, a maioria dos docentes de enfermagem não está suficientemente preparada para oferecer aos alunos um ambiente que favoreça o desenvolvimento do pensamento crítico, uma vez que os próprios docentes não tiveram essa formação nos bancos acadêmicos ${ }^{8,17}$.

Para cumprir bem o papel de educador, o enfermeiro precisa identificar as informações de que os discentes precisam, considerando as limitações do aprendizado e, a partir de então, criar possibilidades de interação e reflexão. Sendo o corpo o veículo do ser-no-mundo, essas possibilidades estão relacionadas com a percepção que esses alunos e professores têm do mundo-da-vida, pois fornecer informações por si, não garante o aprendizado ${ }^{16-18}$.

A literatura aponta que é essencial que o professor domine dez competências, dentre as quais, oito se destacam para o docente do ensino superior: 1- Organizar e dirigir situações de aprendizagem; 2-Administrar a progressão das aprendizagens; 3- Conhecer e fazer evoluir os dispositivos de diferenciação; 4- Envolver os alunos em suas aprendizagens e, portanto, na sua reestruturação de compreensão de mundo; 5- Aprender e ensinar a trabalhar juntos e a se trabalhar com equipes; 6-Dominar e fazer uso de novas tecnologias; 7- Vivenciar e superar os conflitos éticos da profissão e administrar sua formação contínua e permanente; 8- Administrar sua própria formação e enriquecimento contínuo ${ }^{19}$.

Articulando estas competências as práticas docentes, o professor deve saber se relacionar com o outro, ser capaz de refletir sobre seu saber, dinamizando e diversificando suas aulas e métodos de ensino. Deve articular e contextualizar o conhecimento, trabalhando com a problematização e representação da realidade, avaliando diariamente sua prática, colocando o aluno como cogestor de seu processo de construção do conhecimento, valorizando a fala destes, sendo sensível a sua realidade.

Incentivar os alunos em busca de seus ideais e conquistas, nas demandas do mercado, mas não os deixar esquecer de ser leais e éticos com seus semelhantes, reforçando a importância do trabalho em equipe, articulando novas tecnologias na busca de sua formação continuada.

A vertente educação denomina produção, incorporação, reelaboração e aplicação de conhecimentos e tecnologias, através de um processo multidimensional de confronto de perspectivas e prioridades, efetivado na relação dialógica e participativa entre os diferentes saberes dos sujeitos sociais, negociado entre as partes envolvidas no ensino e aprendizagem, promovendo cooperação, solidariedade, troca, superação da realidade almejada, possível ou utópica ${ }^{19}$.

O saber, o saber fazer e o saber conviver, visando desenvolver o aprender a aprender, o aprender a ser, o aprender a fazer, o aprender a viver juntos e o aprender a conhecer, constituem-se atributos indispensáveis à formação do enfermeiro com estímulo às dinâmicas de trabalho em grupos, por favorecerem a discussão coletiva e as relações interpessoais, a valorização das dimensões éticas e humanísticas, desenvolvendo no aluno e no enfermeiro atitudes e valores orientados para a cidadania e para a solidariedade. Nesse sentido, o saber fazer, conviver e ser, será realizado pelo nosso corpo por ser ele a condição e base para nossa existência ${ }^{20,21}$.

Nesse contexto, articular a graduação em enfermagem com o mestrado em enfermagem pode contribuir para a compreensão, interpretação, preservação, reforço, fomento e difusão das culturas nacionais e regionais, internacionais e históricas, em um contexto de pluralismo e diversidade cultural ${ }^{22}$.

\section{Limitações do estudo}

O presente estudo teve como limitação o quantitativo reduzido de participantes, visto que a primeira turma de mestrado profissional possuía poucos enfermeiros, por se tratar de um curso multidisciplinar, e alguns destes enfermeiros já eram docentes, o que mascararia o resultado da pesquisa.

Este estudo visa contribuir com a formação docente para prática profissional do enfermeiro professor do ensino superior, mostrando a este e aos demais profissionais bacharéis que a formação em ensino é necessária para que de fato um conteúdo ministrado em aula, seja de fato agregado como conhecimento aos seus alunos, pois os saberes profissionais não sobrepõem a necessidade da didática e de uma formação docente.

\section{CONSIDERAÇÕES FINAIS}

Estarmos atentos ao mundo em que vivemos, nos moldar e aperfeiçoar ao cenário que estamos é necessário e denota a importância do nosso aperfeiçoamento contínuo. Tal colocação vem ao encontro dos resultados deste estudo, que aborda as mudanças necessárias que devem ocorrer na prática do docente, indo além de novas técnicas didáticas e devendo ser muito mais do que de caráter profissional, envolvendo o âmbito pessoal de forma ascendente e contínua.

Indiferente à tecnologia ou recurso, cabe ao docente o aprimoramento constante da didática e dos recursos utilizados, bem como da sua capacitação e estudo dos temas abordados, trazendo aos alunos sua vivência e experiências práticas, aguçando sua capacidade de assimilação de conteúdos teórico-práticos, sua interação com a realidade e motivação para domínio de conteúdo e excelência em sua formação. 
O professor, como vimos, deixou de ser um transmissor de conhecimento e passou a ser um mediador, ampliando a permuta de informações e incentivando a busca constante do aluno pelo engrandecimento profissional e intelectual, para a construção de um profissional que construa seu arcabouço na construção de uma visão crítica e reflexiva sobre a sua prática de atuação.

Entendemos que a formação docente do enfermeiro para o ensino superior é construída gradativamente ao longo da vida, permitindo a aquisição e a construção dos saberes necessários à sua prática profissional, de forma complexa e marcada por diferentes períodos, diferentes vivências e experiências na sua trajetória pessoal e filosofia profissional.

Enfim, o saber do professor é múltiplo, pois envolve mais que sua prática laboral, conhecimentos teóricos e da prática, proveniente de fontes múltiplas de conhecimentos de naturezas distintas e aplicações diversas na sua atividade laboral. Nesse processo, não podemos deixar de enfocar que a formação deve ser continuada, pois quem deixa de se atualizar acaba caindo no risco de repetir o velho, cair nas mesmices e repetições de práticas docentes já não tão eficazes por terem medo de ousar.

\section{REFERÊNCIAS}

1. Santos GB, Hortale VA. Professional Master's in Public Health: from legal precepts to experience in a research and education institution. Ciênc Saúde Colet [Internet]. 2014 [cited 2020 Feb 15]; 19(7):2143-55. DOI: https://doi.org/10.1590/141381232014197.09072013

2. Vasconcelos FC, Vasconcelos IFG. The Dimensions and Challenges of a Professional Master's Degree. Rev Adm Contemp [Internet]. 2010 [cited 2020 Mar 10]; 14(2):360-6. Available from: https://www.scielo.br/pdf/rac/v14n2/v14n2a11.pdf

3. Lazzari DD, Martini JG, Busana JA. Teaching in higher education in nursing: an integrative literature review. Rev Gaúcha Enferm [Internet]. 2015 [cited 2020 Mar 10]; 36(3):93-101. DOI: http://dx.doi.org/10.1590/1983-1447.2015.03.49670

4. Neto V, Costa M. Saberes docentes: entre concepções e categorizações. Tópicos Educacionais [Internet]. 2017 [cited 2020 Feb 15]; 22(2):76-99. Available from: https://periodicos.ufpe.br/revistas/topicoseducacionais/article/view/110269

5. Coordenação de Aperfeiçoamento de Pessoal de Nível Superior - CAPES (Brasil). Relatório de Avaliação da Área da Enfermagem 2007-2010. [Internet]. [Brasília]: CAPES [cited 2021 Jul 10]. Available from: http://trienal.capes.gov.br/wpcontent/uploads/2010/09/ENFERMAGEM-rel-11set10.pdf

6. Borges EF; Cecílio S. O trabalho docente no brasil [década de 1950 aos dias atuais]: a precarização no contexto de (re)democratização. HOLOS [Internet]. 2018 [cited 2020 Mar 10]; 5:177-94. DOI: https://doi.org/10.15628/holos.2018.6535

7. Trindade R. Teaching and learning in higher education: contribution to reflect on the curricular challenges as epistemological challenges. Rev. Diálogo Educ. [Internet]. 2017 [cited 2020 Mar 10]; 17(53):777-95. DOI: http://dx.doi.org/10.7213/1981416X.17.053.AO04

8. Almeida MM. Pedagogical training and professional development in higher education: professor perspectives. Rev. Bras. Educ. [Internet]. 2020 [cited 2021 Mar 2]; 25:e250008. DOI: http://dx.doi.org/10.1590/s1413-24782019250008

9. Teixeira E. In times of new national curricular guidelines to the nursing graduation course. Rev. Enferm. UFSM [Internet]. 2017 [cited 2020 Mar 2]; 7(2):III-IV. DOI: https://doi.org/10.5902/2179769228859

10. Furlan R. The notion of consciousness in the structure of behaviour (Merleau-Ponty). Psicologia USP [Internet]. 2001 [cited 2020 Mar 2]; 12(1):11-31. DOI: https://doi.org/10.1590/S0103-65642001000100002

11. Giorgi A. Concerning a Serious Mis-Understanding of the Essence of the Phenomenological Method in Psychology. J Phenom Psychol [Internet]. 2008 [cited 2020 Mar 10]; 39(1):33-58. DOI: https://doi.org/10.1163/156916208X311610

12. Fávero AA, Tonieto C, Roman MF. The reflective teacher education: teaching as objective of research. Educação [Internet]. 2013 [cited 2020 Mar 10]; 38(2):277-88. DOI: http://dx.doi.org/10.5902/198464445483

13. Rangel M, Mocarzel MSMV, Pimenta MFB. A Trajetória das Competências e Habilidades em Educação no Brasil: das avaliações em larga escala para as salas de aula. Revista Meta: Avaliação [Internet]. 2016 [cited 2020 Mar 2]; 8(22):28-47. Available from: https://revistas.cesgranrio.org.br/index.php/metaavaliacao/article/view/951

14. Novoa A. To firm the position as a teacher, to affirm the teaching profession. Cad Pesq [Internet]. 2017 [cited 2020 Mar 2]; 47(166):1106-33. DOI: https://doi.org/10.1590/198053144843

15. Medeiros ESM, Prestes DRM, Pignata EKAA, Furtado RMS. Profile of the nursing teacher and his perception on pedagogical training. Rev Recien [Internet]. 2018 [cited 2020 Feb 15]; 8(24):42-53. DOI: https://doi.org/10.24276/rrecien23583088.2018.8.24.42-53

16. Santos EE. Merleau-Ponty: beyond the philosophies of certainties. Ekstasis: Rev Hermenêutica e Fenomenologia [Internet]. 2016 [cited 2020 Feb 15]; 5(2):69. DOI: https://doi.org/10.12957/ek.2016.28267

17. Oliveira RD. Inovar em sala de aula, novas tecnologias, grandes Conhecimentos. Fronteiras: Revista de História [Internet]. 2014 [cited 2020 Mar 2]; 16(28):166-81. Available from: https://pdfs.semanticscholar.org/1de4/3cb1b585ef7630e712be71aa7b92bbdbd516.pdf

18. Azevedo DS, Caminha IO. Ser no mundo, mundo vivido e corpo próprio segundo Merleau-Ponty. Dialektiké [Internet]. 2017 [cited 2020 Nov 20]; 1(2):15-37. DOI: https://doi.org/10.15628/dialektike.2015.3009

19. Silva JP, Gonçalves MFC, Andrade LS, Monteiro EMLM, Silva MAI. Health promotion in primary education: perceptions of bachelor's degree with a teaching diploma in nursing students. Rev Gaúcha Enferm. [Internet]. 2018 [cited 2020 Feb 15]; 39:e2017-0237. DOI: https://doi.org/10.1590/1983-1447.2018.2017-0237 
20. Farias MS, Brito LLMS, Santos AS, Guedes MVC, Silva LF, Chaves EMC. Reflections on knowledge, knowing-how and how to behave in nursing training. REME - Rev Min Enferm. [Internet]. 2019 [cited 2020 Mar 20]; 23:e-1207. DOI: https://doi.org/10.5935/1415-2762.20190055

21. Pires Ferreira MEM. The body according to Merleau-Ponty and Piaget. Ciênc. cogn. [Internet]. 2010 [cite 2020 Nov 20]; 15(3):47-61. Available from: http://pepsic.bvsalud.org/scielo.php?script=sci_arttext\&pid=S1806$58212010000300006 \& \operatorname{lng}=\mathrm{pt \& nrm}=$ iso

22. Valente GSC, Cortez EA, Cavalcanti ACD, Cosme FSMN, Gonçalves LC. Nursing mentoring in primary care: building skills from practice. Rev Enferm UFPE [Internet]. 2014 [cited 2020 Dec 11]; 8(9):3047-58. Available from: https://periodicos.ufpe.br/revistas/revistaenfermagem/article/download/10024/10411 